
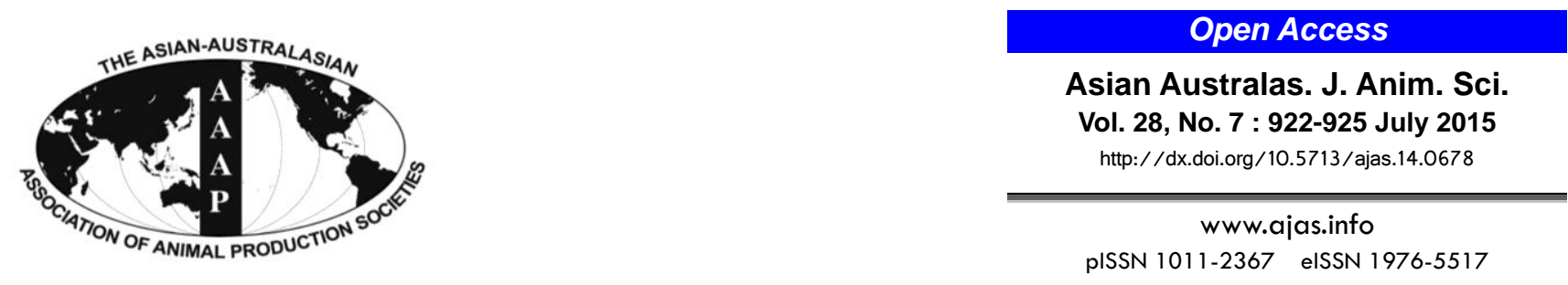

\title{
Estimation of Genetic Parameters for Pork Belly Components in Yorkshire Pigs
}

\author{
H. S. Kang, B. M. Lopez, T. H. Kim, H. S. Kim, S. H. Kim ${ }^{1}$, K. C. Nam, and K. S. Seo* \\ Department of Animal Science and Technology, Sunchon National University, Suncheon 540-742, Korea
}

\begin{abstract}
This study was conducted to estimate the genetic parameters for pork belly traits and muscles in Yorkshire pigs. Each pork belly was cut into nine parts perpendicular to the thoracic vertebrae (6th to 14th). Traits of belly muscles including the deep pectoral, latissimus dorsi, cutaneous trunci, rectus abdominis, external and internal abdominal oblique from 382 purebred pigs were recorded and analyzed using SAS Package (9.1) and Derivative-free restricted maximum likelihood methods. Heritability estimates for belly traits ranged from 0.27 to 0.49 , while they were 0.12 to 0.66 for belly muscles. Moderate to high heritability estimates were noted in belly weight (0.33), belly length (0.28), and belly width (0.49). In belly muscles, the latissimus dorsi and deep pectoral, which are located only in the 6th to 9 th vertebrae sections, were found to have heritability estimates ranging from 0.21 to 0.29 and 0.23 to 0.35 , respectively. Strong heritability estimates were observed in the 7 th to 13 th sections of cutaneous trunci muscle ranging from 0.42 to 0.66 . Genetic correlations of latissimus dorsi $\mathrm{m}$. with belly length were positive $(0.50)$, while cutaneous trunci m. with belly weight also revealed a positive relationship that ranged from 0.35 to 0.47 . The estimated genetic parameters indicate that belly weight can be improved by genetic selection. Differences in the levels of heritability occurred among various parameters of Yorkshire pork belly, which should be considered when performing selection to improve pork belly quality. Moreover, these results can provide valuable information that can be used as the basis for further investigations to improve pork belly. (Key Words: Genetic Parameters, Pork Belly, Yorkshire Pigs)
\end{abstract}

\section{INTRODUCTION}

The cost of pork is determined by the market value of its primal cuts (Hermesch, 2008). One of these cuts is the belly, which is a boneless cut of fatty meat from the underside between the legs of the pig. Pork belly is one of the most valuable primal cuts of the pig carcass (Marcoux et al., 2007), with different uses in different markets. In the Japanese market, pork belly is used for the production of bacon; therefore, the presence of a well-defined streak and a higher proportion of lean meat to fat are essential. Conversely, the belly is not used for bacon production in Singapore, but instead sold in strips for use in stir-fry type meals. South Korean consumers show very strong preferences for particular parts of the pig and to pork that is

\footnotetext{
* Corresponding Author: K. S. Seo. Tel: +82-61-750-3231, Fax: +82-61-750- 3230, E-mail: sks@ sunchon.ac.kr

${ }^{1}$ Pig Gene Korea Co. Ltd., Anseong 456-749, Korea.

Submitted Sept. 3, 2014; Revised Nov. 26, 2014; Accepted Feb. 13, 2015
}

higher in fat. Hence, pork belly is the most preferred meat of consumers in South Korea (Oh and See, 2012; Seo et al., 2012). Accordingly, it is essential to predict the composition of the belly and have a good understanding of the factors that affect belly composition to meet the demands of each market (Hermesch and O'Shea, 2005). Majority of pork belly in Korea is coming from crossbreds and generally from three-way crosses (LandracexYorkshirexDuroc) (Kim et al., 2006). For this reason, it is worth to investigate the heritability of pork belly from one of the parent lines. Furthermore, carcass composition traits are highly heritable and respond very favorably to genetic selection (Newcom et al., 2002). For any selection program to be advantageous, variance components and genetic parameter estimates for the traits in question must be identified.

Although genetic parameters for pork belly have been extensively reported (Schroder and Rust, 1974; Hermesch and O'Shea, 2005; Correa et al., 2008; Hermesch, 2008), heritability estimates and genetic correlations for specific 
muscles comprising pork belly have not. This study was conducted to estimate the heritability for pork belly traits in Yorkshire pigs, especially the muscles comprising the pork belly, and their genetic relationships with other traits.

\section{MATERIALS AND METHODS}

\section{Data utilized}

A total of 382 purebred Yorkshire pigs from six different pig farms were utilized in this study. Pigs were fed the same commercial feed, raised under similar conditions and transported from the farm to the slaughterhouse. The majority of animals were entire males (334 castrated pigs). All the measurements for pork belly traits used in this study were recorded by the Korea Institute for Animal Products Quality Evaluation (KAPE), which is authorized by the South Korean government to grade animal products.

Carcass weight, body width and length, and backfat thickness (BF) were measured immediately after slaughter. The BF was measured on all live animals ultrasonically at the tenth rib $4 \mathrm{~cm}$ from the midline and adjusted to $90 \mathrm{~kg}$ using the formula below:

$$
\begin{aligned}
& \mathrm{BF}=\text { backfat measurement } \\
& +\frac{(90-\text { test end weight }) \times \text { backfat mesurements }}{(\text { test end weight }-11.34)}
\end{aligned}
$$

Twenty-four hours after slaughter, bellies were separated from the loin between the dorsal end of the $m$. serratus ventarlis to the middle of the $m$. latissimus dorsi. Only the right sides of the bellies were used. The belly weight, length, width, total area, and thickness were obtained before the belly was divided. The belly was ribbed by a cut perpendicular to the thoracic vertebrae (6th to 14 th), resulting in nine sections. The areas $\left(\mathrm{cm}^{2}\right)$ of each belly muscle in each section were recorded by image scanning. Only the following major muscles in the belly were included in the study, the deep pectoral, latissimus dorsi, cutaneous trunci, rectus abdominis, and the external and internal abdominal oblique. The rectus abdominis and external abdominal oblique muscles are located in the 7th to 14th thoracic vertebra sections, while deep pectoral and latissimus dorsi muscles are only found in the 6th to 9th thoracic vertebrae and the long cutaneous trunci muscle is situated from the 6 th to 14 th thoracic vertebrae sections. Images were recorded using a commercial digital camera (Canon A-80, 4 megapixels) with an integrated lens. A 5 $\mathrm{mm}$ grid was employed across the image capture area to ensure that no distortion was present in the area to be measured. A $30 \mathrm{~cm}$ ruler scale was attached to the front of and below the hinged top. Each belly section was placed on the hinged top skin side down with the belly/loin interface facing the camera. A commercial software package (ImagePro Plus, Media Cybernatics, Bethesda, MD, USA) was used for analysis of the digital image of each belly and a number of area measurements of the belly were derived.

\section{Statistical analysis}

Statistical package SAS version 9.1 was employed for the analyses. Elementary statistics were conducted using the MEANS procedure. Initial computations were performed using SAS Proc general linear model to evaluate nongenetic factors; specifically, fixed effects to be included in the model. Significant effects $(p<0.01)$ of test day (covariate) and YS (four classes) were found for almost all traits. Restricted maximum likelihood method in WOMBAT (Meyer, 2007) was used to estimate variance, covariance components, heritability and genetic correlations with their standard errors. The method enabled the inclusion of fixed effect, covariates and random genetic effects in the model. Univariate analysis for all traits was undertaken to estimate heritabilities for each trait while bivariate analysis was used to establish genetic correlation between traits. The following animal model was applied for analysis to estimate genetic parameters:

$$
Y_{i j k}=\mu_{i}+Y S_{i j}+a_{i j k}+\beta A G E_{i j k}(\operatorname{cov})+e_{i j k}
$$

where, $\mathrm{Y}_{\mathrm{ijk}}=$ observation for the trait $i ; \mu_{\mathrm{i}}=$ overall mean for trait $i ; \mathrm{YS}_{\mathrm{ij}}=\mathrm{j}^{\text {th }}$ year-season effect of the $\mathrm{i}^{\text {th }}$ trait; $\mathrm{a}_{\mathrm{ijk}}=$ animal random effect; $\beta=$ covariate of number of test day; $\mathrm{AGE}_{\mathrm{ijk}}=$ number of test days; $\mathrm{e}_{\mathrm{ijk}}=$ random error. $\mathrm{six}$ generations of pedigree information from 35,569 animals from January 1998 to July 2012 were included in the analysis. The subset of animals that had belly data documented came from 382 pigs (334 barrows and 48 gilts).

\section{RESULTS AND DISCUSSION}

The elementary statistics of the recorded traits are summarized in Table 1. The average weight in kilograms with standard deviation of the carcass and belly were 89.69 (9.23) and 7.39 (1.05), respectively. The average lean content of the belly was $45 \%$. The mean area of the belly was 4,642.81 $\mathrm{cm}^{2}$, with a standard deviation of 737.29. Among the belly muscles, cutaneous trunci had the highest area, with an average of $433.75 \mathrm{~cm}^{2}$.

\section{Heritability estimates}

The heritability estimates $\left(h^{2}\right)$ with standard error for belly traits are presented in Table 2. The estimated heritability of belly traits ranged from 0.27 to 0.49 , with values for weight, length and width of $0.33 \pm 0.06,0.28 \pm 0.08$ and $0.49 \pm 0.08$, respectively. Newcom et al. (2002) reported that the heritability estimate for pork belly was 0.51 based 
Table 1. Basic statistics for carcass traits, belly traits and muscles

\begin{tabular}{|c|c|c|c|c|}
\hline Trait & Min & Max & Mean & SD \\
\hline \multicolumn{5}{|l|}{ Carcass traits } \\
\hline Carcass weight (kg) & 70 & 116 & 89.69 & 9.23 \\
\hline Carcass body length (mm) & 730 & 925 & 833 & 27.82 \\
\hline Backfat thickness (mm) & 9 & 35 & 23.02 & 5.10 \\
\hline \multicolumn{5}{|l|}{ Belly traits } \\
\hline Belly weight** (kg) & 5.1 & 12.5 & 7.39 & 1.05 \\
\hline Belly thickness* (mm) & 22 & 69 & 45.66 & 13.36 \\
\hline Belly length** (mm) & 454 & 612 & 534.37 & 25.89 \\
\hline Belly width** (mm) & 245 & 395 & 300 & 22.34 \\
\hline Belly area** $\left(\mathrm{cm}^{2}\right)$ & $3,236.50$ & $7,812.03$ & $4,642.81$ & 737.29 \\
\hline Belly muscle area $\left(\mathrm{cm}^{2}\right)$ & $1,461.31$ & $3,545.68$ & $2,087.79$ & 322.72 \\
\hline Belly fat area $\left(\mathrm{cm}^{2}\right)$ & $1,670.20$ & $3,961.42$ & $2,394.08$ & 582.34 \\
\hline Belly muscle ratio (\%) & 0.31 & 0.69 & 0.45 & 0.06 \\
\hline \multicolumn{5}{|l|}{ Belly muscles } \\
\hline Deep pectoral m. $\left(\mathrm{cm}^{2}\right)$ & 37.31 & 180.37 & 99.04 & 25.23 \\
\hline Latissimus dorsi $\mathrm{m} .\left(\mathrm{cm}^{2}\right)$ & 101.06 & 367.47 & 205.59 & 37.03 \\
\hline Cutaneous trunci m. $\left(\mathrm{cm}^{2}\right)$ & 233.36 & 735.80 & 433.75 & 81.63 \\
\hline Rectus abdominis m. $\left(\mathrm{cm}^{2}\right)$ & 108.92 & 538.56 & 205.31 & 46.29 \\
\hline External abdominal oblique $\mathrm{m} .\left(\mathrm{cm}^{2}\right)$ & 168.58 & 809.25 & 333.29 & 66.88 \\
\hline Internal abdominal oblique $\mathrm{m} .\left(\mathrm{cm}^{2}\right)$ & 25.21 & 197.62 & 92.85 & 27.81 \\
\hline
\end{tabular}

SD, standard deviation.

${ }^{*}$ Hot carcass. ${ }^{* *}$ Cold carcass.

Table 2. Heritability estimates $\left(h^{2}\right)$ and standard error (SE) for belly traits

\begin{tabular}{lcc}
\hline Trait & $\mathrm{h}^{2}$ & $\mathrm{SE}$ \\
\hline Belly weight & 0.33 & 0.06 \\
Belly length & 0.28 & 0.08 \\
Belly width & 0.49 & 0.08 \\
Belly muscle area & 0.45 & 0.09 \\
Belly fat area & 0.27 & 0.08 \\
\hline
\end{tabular}

on an investigation of 456 homozygous halothane normal purebred Yorkshire, Duroc and other breeds, while Hermesch (2008) reported estimates ranging from 0.23 to 0.34 for belly traits in 2,403 pigs. The estimates of heritability for the area of belly muscle were higher (0.45) than for the area of fat (0.27). Tholen et al. (2003) reported that the estimates of heritability for lean meat content of the belly ranged from 0.27 to 0.31 based on two independent populations of fattening pigs.

Table 3 shows the heritability estimates and standard errors for belly muscles by section. Deep pectoral and latissimus dorsi muscles, which were present only in the 6th to 9 th thoracic vertebrae, were found to have moderate to high heritability estimates of 0.23 to 0.35 and 0.21 to 0.29 , respectively. Estimates for the heritability of cutaneous trunci muscles were moderate to high, ranging from 0.12 in the 14th thoracic vertebra to 0.66 in the 11th thoracic vertebra. Heritability estimates for the rectus abdominis varied from 0.14 to 0.45 , while they were 0.13 to 0.64 for the external abdominal oblique muscle. Overall, the measured heritability for belly muscles varied greatly by section and within muscle. To the extent of our knowledge, this is the first study to provide information regarding genetic parameters for muscles of the belly.

\section{Genetic correlations}

The genetic correlations among belly traits are presented in Table 4. The latissimus dorsi showed low positive genetic correlations with belly weight (0.27). Genetic correlations between belly weight and the cutaneous trunci muscle ranged from 0.35 to 0.47 . Belly

Table 3. Heritability estimates and standard errors (SE) for belly muscles by section

\begin{tabular}{|c|c|c|c|c|c|c|c|c|c|}
\hline Trait & 6th & 7th & 8th & 9th & 10th & 11th & 12th & 13th & 14th \\
\hline Deep pectoral m. $\left(\mathrm{cm}^{2}\right)$ & $0.35 \pm 0.08$ & $0.31 \pm 0.08$ & $0.23 \pm 0.07$ & $0.24 \pm 0.08$ & - & - & - & - & - \\
\hline Latissimus dorsi m., $\left(\mathrm{cm}^{2}\right)$ & $0.25 \pm 0.07$ & $0.29 \pm 0.09$ & $0.21 \pm 0.09$ & $0.26 \pm 0.08$ & - & - & - & - & - \\
\hline Cutaneous trunci $\mathrm{m} . \mathrm{cm}^{2}$ & $0.24 \pm 0.07$ & $0.48 \pm 0.06$ & $0.42 \pm 0.08$ & $0.54 \pm 0.07$ & $0.59 \pm 0.07$ & $0.66 \pm 0.08$ & $0.55 \pm 0.09$ & $0.46 \pm 0.07$ & $0.12 \pm 0.07$ \\
\hline Rectus abdominis m. $\left(\mathrm{cm}^{2}\right)$ & - & $0.20 \pm 0.06$ & $0.44 \pm 0.06$ & $0.38 \pm 0.07$ & $0.45 \pm 0.08$ & $0.36 \pm 0.06$ & $0.22 \pm 0.09$ & $0.20 \pm 0.08$ & $0.14 \pm 0.09$ \\
\hline External abdominal oblique $\mathrm{m} .\left(\mathrm{cm}^{2}\right)$ & - & $0.13 \pm 0.06$ & $0.30 \pm 0.06$ & $0.32 \pm 0.07$ & $0.21 \pm 0.08$ & $0.30 \pm 0.07$ & $0.32 \pm 0.07$ & $0.64 \pm 0.07$ & $0.41 \pm 0.07$ \\
\hline
\end{tabular}


Table 4. Genetic correlations among belly traits

\begin{tabular}{|c|c|c|c|c|c|c|c|c|c|c|}
\hline Trait & 1 & 2 & 3 & 4 & 5 & 6 & 7 & 8 & 9 & 10 \\
\hline 1 & 1 & & & & & & & & & \\
\hline 2 & 0.5704 & 1 & & & & & & & & \\
\hline 3 & 0.4594 & 0.1377 & 1 & & & & & & & \\
\hline 4 & 0.2744 & 0.5058 & 0.0671 & 1 & & & & & & \\
\hline 5 & 0.4994 & 0.0925 & 0.4725 & 0.1487 & 1 & & & & & \\
\hline 6 & 0.7452 & 0.6353 & 0.2156 & 0.0679 & -0.1254 & 1 & & & & \\
\hline 7 & 0.3566 & -0.2715 & 0.4044 & 0.0754 & 0.7527 & -0.2069 & 1 & & & \\
\hline 8 & 0.4728 & 0.1043 & 0.3732 & 0.2743 & 0.3979 & 0.2405 & 0.2670 & 1 & & \\
\hline 9 & 0.3526 & 0.0075 & 0.4110 & 0.1501 & 0.5280 & 0.0864 & 0.4679 & 0.5923 & 1 & \\
\hline 10 & 0.4130 & 0.2950 & 0.2339 & 0.3949 & 0.1696 & 0.3646 & 0.0069 & 0.9087 & 0.6236 & 1 \\
\hline
\end{tabular}

1, belly weight; 2, belly length; 3, belly width; 4, latissimus dorsi m.; 5, area of belly muscle; 6, area of belly fat; 7, cutaneous trunci m. (9th thoracic vertebra); 8 , cutaneous trunci $m$. (10th thoracic vertebra); 9 , cutaneous trunci $\mathrm{m}$. (11th thoracic vertebra); 10 , cutaneous trunci m. (12th thoracic vertebra).

length had low genetic correlation with cutaneous trunci muscle, which was as expected because the cutaneous trunci muscle attaches laterally to the belly. In comparison, belly width had moderate genetic association with the cutaneous trunci muscle, ranging from 0.23 to 0.41 . Low (0.16) to high $(0.75)$ genetic correlations were observed between the area of belly muscle and cutaneous trunci muscle. Comparatively, genetic correlations between lean meat content of the belly and weight of other carcass cuts varied from 0.84 to 0.99 in a study conducted by Tholen et al. (2003), with the majority of estimates being above 0.95 . Genetic correlations obtained in this study showed that selection to improve one trait would be associated with advantageous changes in other traits.

\section{CONCLUSION}

Few studies comparing genetic parameters for belly traits and muscle have been conducted to date. The results presented herein show that each of the components of the belly is highly heritable as the cutaneous trunci muscle, which indicates that a response to selection for these component traits is possible. Moreover, the differences in the levels of heritability observed among the various parameters of Yorkshire pork belly should be taken into account when performing selection to improve pork quality. However, genetic enhancement of individual muscle characteristics requires specific measurements. Overall, the results presented herein provide valuable information that can be used as bases for further investigations to improve pork belly.

\section{ACKNOWLEDGMENTS}

This work was carried out with the support of "Cooperative Research Program for Agriculture Science \& Technology Development (Project No. PJ009274)" Rural Development Administration, Republic of Korea.

\section{REFERENCES}

Correa, J. A., C. Gariepy, M. Marcoux, and L. Faucitano. 2008. Effects of growth rate, sex and slaughter weight on fat characteristics of pork bellies. Meat Sci. 80:550-554.

Hermesch, S. and J. M. O'Shea. 2005. genetic parameters for characteristics of pork bellies. Proc. Assoc. Advmt. Anim. Breed. Genet. 16:137-140.

Hermesch, S. 2008. Genetic relationships between composition of pork bellies and performance, carcass and meat quality traits. Animal 2:1178-1185.

Kim, J. H., B. Y. Park, Y. M. Yoo, S. H. Cho, I. H. Hwang, P. N. Seong, K. H. Hah, and M. J. Lee. 2006. Characteristics of carcass and meat quality for Landrace, Yorkshire, Duroc and their crossbreeds. J. Anim. Sci. Technol. (Korea). 48:101-106.

Marcoux, M., C. Pomar, L. Faucitano, and C. Brodeur. 2007. The relationship between different pork carcass lean yield definitions and the market carcass value. Meat Sci. 75:94-102.

Meyer, K. 2007. WOMBAT-A tool for mixed model analyses in quantitative genetics by restricted maximum likelihood (REML). J. Zhejiang Univ. Sci. B 8:815-821.

Newcom, D. W., T. J. Baas, J. W. Mabry, and R. N. Goodwin. 2002. Genetic parameters for pork carcass components. J. Anim. Sci. 80:3099-3106.

Oh, S. H. and M. T. See. 2012. Pork preference for consumers in China, Japan and South Korea. Asian Australas. J. Anim. Sci. 25:143-150.

Schroder, B. G. and R. E. Rust. 1974. Composition of pork bellies. II. Compositional variation between and within animals and the relationship of various carcass measurements with the chemical components of the belly. J. Anim. Sci. 39:1037-1044.

Seo, S. H., E. M. Kim, and Y. B. Kim. 2012. Preferences and consumption patterns of consumer to develop processed pork products for export. Korean J. Food Sci. Anim. Resour. 32:1832.

Tholen, E., U. Baulain, M. D. Henning, and K. Schellander. 2003. Comparison of different methods to assess the composition of pig bellies in progeny testing. J. Anim. Sci. 81:1177-1184. 